Portland State University

PDXScholar

Summer 8-14-2014

\title{
Emerging Lexical Organization from Intentional Vocabulary Learning
}

Adam Jones

Portland State University

Follow this and additional works at: https://pdxscholar.library.pdx.edu/open_access_etds

Part of the First and Second Language Acquisition Commons Let us know how access to this document benefits you.

Recommended Citation

Jones, Adam, "Emerging Lexical Organization from Intentional Vocabulary Learning" (2014). Dissertations and Theses. Paper 1949.

https://doi.org/10.15760/etd.1948

This Thesis is brought to you for free and open access. It has been accepted for inclusion in Dissertations and Theses by an authorized administrator of PDXScholar. Please contact us if we can make this document more accessible: pdxscholar@pdx.edu. 
Emerging Lexical Organization from Intentional Vocabulary Learning

by

Adam Jones

A thesis submitted in partial fulfillment of the requirements for the degree of

\author{
Master of Arts \\ in \\ Teaching English to Speakers of Other Languages
}

Thesis Committee:

Lynn Santelmann, Chair

Tetyana Sydorenko

Kathryn Harris

Portland State University

2014 
(C) 2014 Adam Jones 


\begin{abstract}
The role that vocabulary learning plays in second language acquisition has been receiving increased attention from both teachers and researchers. However, there is still much that is not known about the processes through which new words become functioning components of the mental lexicon. This study used a word association test (WAT) to investigate how new words are initially integrated into the lexicon immediately after being studied for the first time. This initial lexical organization of new words was compared with the existing lexical organization of well-known items. In addition, this study investigated how sentence writing, thought to encourage deeper levels of processing, affected how the new words were initially integrated into the lexicon.

The participants in this study were 16 volunteers from an Intensive English Language Program. The participants first completed a vocabulary knowledge scale to assess if they knew the new vocabulary words. Then, the participants spent 20 minutes learning the words - either through writing sentences with the words or through choosing their own method of study. Immediately after the 20 minute learning period, the WAT was administered. The results of the WAT indicated that the new words were being organized into the lexicon through meaning-based connections just as the well-known words were. The majority of the meaning-based lexical organization was based on equivalent meaning connections such as synonymy or superordination. The sentence writing condition correlated with a decrease in meaning-based WAT associations for the new words, which indicated that sentence writing may have affected the lexical integration in unexpected ways. Finally, unanticipated WAT response patterns indicated that other contextual factors may have also influenced the responses.
\end{abstract}




\section{Acknowledgements}

I would like to thank the Portland State University Department of Applied Linguistics. In particular, I would like to thank my committee, especially my faculty advisor Lynn Santelmann, who provided me with invaluable guidance and feedback. I would also like to thank Portland State University's Intensive English Language Program (IELP) and all the instructors who invited me to their classes so that I could recruit participants for this study. I am also grateful for the assistance of the IELP students whose participation made this study possible. Finally, I would like to thank Ellen Jean for generously assisting me through her knowledge of statistics and SPSS. 
Table of Contents

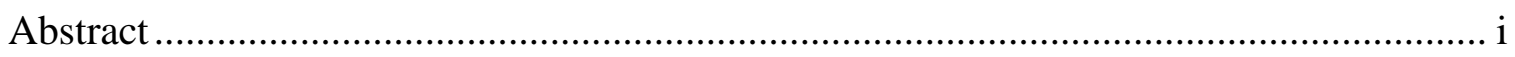

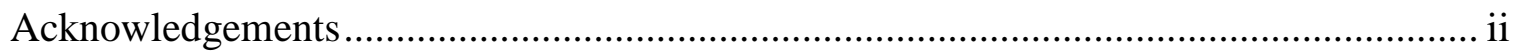

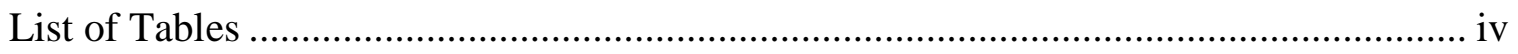

Chapter One

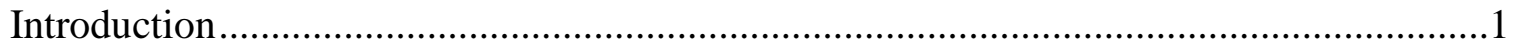

Chapter Two

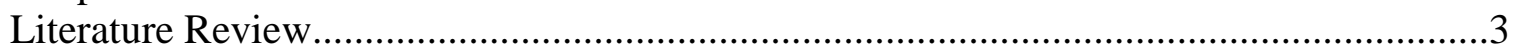

Chapter Three

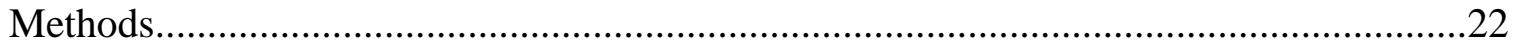

Chapter Four

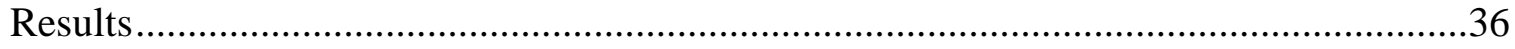

Chapter Five

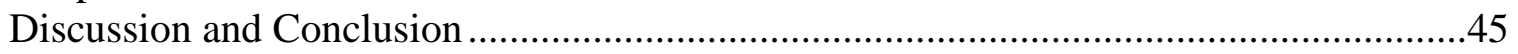

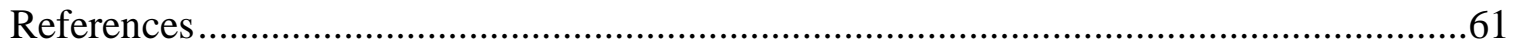

Appendix A

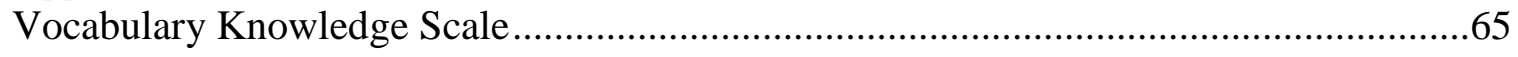

Appendix B

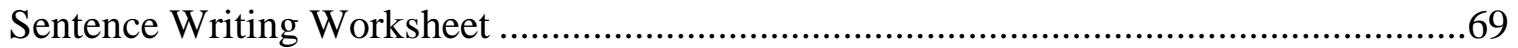

Appendix C

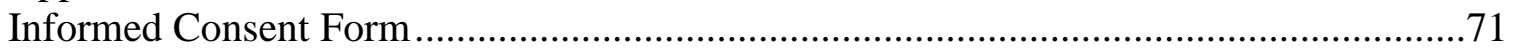

Appendix D

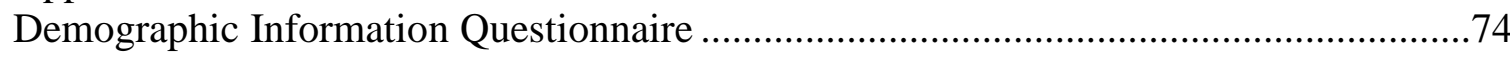




\section{List of Tables}

Table 2.1

Nation's (2001) Aspects of Word Knowledge.

Table 2.2

Fitzpatrick's (2006) Word Association Meaning-Based Subcategories

Table 2.3

Fitzpatrick and Izura's (2011) Word Association Categories. 18

Table 3.1

High and Low-Frequency WAT Cue-Words

Table 3.2

Low-Frequency Word Definitions.

Table 3.3

Word Association Response Categories

Table 4.1

VKS Instances of Self-Reported Understanding of Meaning

Table 4.2

Distribution of WAT Responses in the Main Categories

Table 4.3

Distribution of WAT Responses in the Meaning-Specific Sub-Categories.

Table 4.4

Collapsed Main Categories: Meaning and Non-Meaning 


\section{Chapter One}

\section{Introduction}

When I was actively learning Spanish, I carried stacks of vocabulary cards with me wherever I went, preparing for that exciting time when I would be able to read my favorite authors untranslated and, more often than I'd like to admit, cramming anxiously for an imminent exam. As a language learner, now as well as in the past, vocabulary has always seemed to be an especially immediate and salient element of language — a feeling that recalls the statement, "Without grammar very little can be conveyed, without vocabulary nothing can be conveyed" (Wilkins, 1972, pp. 111-112). As a teacher, I have observed this same visceral response to vocabulary in my students. I have consistently seen less-engaged students perk up in tandem with their more motivated peers when I explicitly talk about vocabulary and vocabulary learning strategies.

My interest in vocabulary learning as well as an interest in semiotics caused me to become curious about the possible connection between vocabulary learning and the different ways a word's meaning may be represented in the mind while it is studied. A prime motivation for this study was my interest in the different ways a learner might work with new vocabulary words' meanings, thereby manipulating the way those words' meanings are represented in the mind while studying. To this end, this study sought to look beyond whether specific vocabulary learning strategies lead to retention and, instead, investigate the mental processes through which newly learned vocabulary is integrated into the lexicon in different learning conditions. The study investigated whether new words were being integrated into the lexicon through form-based, positionbased, or meaning-based connections. It is through this lexical integration that 
vocabulary items become functional elements of the lexicon that can be activated, not only for a test, but also when encountered in a text, needed in conversation, and even as a part of a learner's own internal dialogue.

To investigate the effect that different ways of working with words' meanings may have on how those words are integrated into the lexicon, the participants in this study were asked to learn previously unknown vocabulary words in one of two possible conditions. Participants in the treatment group completed a sentence writing task with the target words while participants in the control group were simply instructed to do their best to learn the words.

After studying the words, each participant took part in a word association test (WAT). The WAT was used to investigate how the newly studied words were being integrated into the participants' lexicons in the different intentional learning conditions mentioned above. Many of the previous studies that employed WATs to investigate the lexicon used familiar vocabulary. In contrast, this study used words that were not previously known to the participants to investigate emerging lexical organization as it happened after a short period of intentional vocabulary learning. By investigating the patterns in the word association responses that participants produced immediately after a period of intentional learning, this study sought to reveal new information about how words are integrated into the lexicon thereby adding to our understanding of both intentional vocabulary learning and the mental lexicon.

After the literature review, I will explain this study's research methodology. Following that, I will present the results of the study before discussing those results and their implications for language teaching and future research. 


\section{Chapter Two}

\section{Literature Review}

This literature review will provide background on the concepts and previous research that is relevant to this study. First, I will review the role that vocabulary learning plays in language acquisition as well as what must be known about a word for it to be considered fully learned. Second, I will review the differences between incidental and intentional vocabulary learning, and will explain the role of intentional vocabulary learning, which is the type of learning featured in my experiment. Third, I will review how the mental lexicon is organized and how words are integrated into it. This discussion will help to define the territory that my study's Word Association Test (WAT) investigated. Next, I will review vocabulary learning strategies in relation to how they may affect the way that vocabulary is integrated into the mental lexicon. Finally, I will review word association studies, and how they have been used to investigate vocabulary learning and the lexicon.

\section{Vocabulary Learning in SLA}

Since in the early 1980s, L2 vocabulary learning and the L2 lexicon have received an increasing amount of attention (Singleton, 1999), which reflects the importance that vocabulary learning and the lexicon play in L2 acquisition. I will use the term vocabulary to refer to a discrete lexical item, or to collections of discrete lexical items, and will use the term lexicon to refer to the collection of vocabulary as it exists in the mind complete with the connections and associations that exist between each item. 
In order to understand both spoken and written English an individual must have a lexicon that boasts an impressive number of word families. A word family includes the base form of a word as well as its inflected and derived forms (Hirsh \& Nation, 1992). For example, the adjective happy is a base form, and its word family includes the noun happiness and the adverb happily. The importance of vocabulary is illustrated by Nation and Beglar (2007), who noted that an individual's vocabulary must cover $98 \%$ of the words in a text for that text to be understood when read unassisted. They noted that in order to have $98 \%$ coverage of spoken English, newspapers, and novels, a speaker must know 7,000, 8,000, and 9,000 word families, respectively. The impressive size of these figures illustrates the importance of the lexicon in L2 learning.

Acknowledging the importance of vocabulary and the lexicon in L2 learning leads to the question of what it means to truly know a word. Nation (2001) responded to this question by identifying nine aspects of vocabulary word knowledge, which he classified as pertaining to either form, meaning, or use. Table 2.1 displays the aspects of word knowledge as identified by Nation (2001, p. 27). The present study investigated connections in the lexicon related the form, meaning, and use aspects of word knowledge, but paid special attention to the meaning aspect by distinguishing between different types of meaning-based connections in the lexicon. 
Table 2.1: Nation's (2001) Aspects of Word Knowledge

\begin{tabular}{|c|c|c|}
\hline \multirow[t]{6}{*}{ form } & \multirow[t]{2}{*}{ spoken } & What does the word sound like? \\
\hline & & How is the word pronounced? \\
\hline & \multirow[t]{2}{*}{ written } & What does the word look like? \\
\hline & & How is the word written and spelled? \\
\hline & \multirow[t]{2}{*}{ word parts } & What parts are recognizable in this word? \\
\hline & & $\begin{array}{l}\text { What word parts are needed to express the } \\
\text { meaning? }\end{array}$ \\
\hline \multirow[t]{6}{*}{ meaning } & \multirow[t]{2}{*}{ form and meaning } & What meaning does this word form signal? \\
\hline & & $\begin{array}{l}\text { What word form can be used to express this } \\
\text { meaning? }\end{array}$ \\
\hline & \multirow[t]{2}{*}{ concept and referents } & What is included in the concept? \\
\hline & & What items can the concept refer to? \\
\hline & \multirow[t]{2}{*}{ associations } & What other words does this make us think of? \\
\hline & & What other words could we use instead of this one? \\
\hline \multirow[t]{6}{*}{ Use } & \multirow[t]{2}{*}{ grammatical functions } & In what pattern does the word occur? \\
\hline & & In what patterns must we use this word? \\
\hline & \multirow[t]{2}{*}{ collocations } & What words or types of words occur with this one? \\
\hline & & $\begin{array}{l}\text { What words or types of words must we use with } \\
\text { this one? }\end{array}$ \\
\hline & \multirow[t]{2}{*}{\begin{tabular}{|l} 
constraints on use \\
(register, frequency ....)
\end{tabular}} & $\begin{array}{l}\text { Where, when, and how often would we expect to } \\
\text { meet this word? }\end{array}$ \\
\hline & & Where, when, and how often can we use this word? \\
\hline
\end{tabular}

Although all of Nation's aspects of word knowledge are present to some degree when a word is fully integrated into the lexicon, Schmitt (2008) noted that it may be the case that not all of these aspects of word knowledge are mastered concurrently even if they are learned at the same time. Schmitt posited that different aspects of word knowledge may be more easily acquired through different types of learning. For example, Schmitt noted that meaning and word form may be more amenable to 
intentional learning while collocation and intuitions of frequency may be better acquired through incidental learning. Because it is necessary for learners to acquire a large amount of word knowledge for a large amount of vocabulary, it is worth investigating how different approaches to vocabulary learning affect how new words are associated with different aspects of word knowledge through connections in the lexicon.

\section{Incidental and Intentional Vocabulary Learning}

Although the importance of vocabulary in L2 learning is now generally understood in the TESOL field (Folse, 2004), questions remain about how vocabulary learning is best facilitated. Two different approaches to vocabulary learning, which are often presented as in opposition, are incidental and intentional vocabulary learning. This study investigates intentional vocabulary learning and takes the position, that while incidental learning is important, intentional learning is also necessary.

Incidental learning takes place when new vocabulary is picked up or consolidated in a context with a communicative aim (Schmitt, 2008). In this type of learning the focus is primarily on the message rather than on the word itself. Incidental vocabulary learning may occur through exposure from reading or listening, or from consolidating knowledge through use.

Intentional learning, as the name implies, takes place when explicit and conscious attention is given to particular lexical items without necessarily embedding them in a communicative task (Schmitt, 2008). An example of intentional vocabulary learning is vocabulary word lists, which most language learners and teachers are familiar with. Learners often make or are provided with lists of vocabulary to learn. The words in 
vocabulary lists are generally accompanied by definitions, translations, or other aspects of word knowledge that learners can use to learn the words.

Schmitt (2008) noted that Incidental learning is valuable because it can provide repeated exposures to lexical items in different contexts. In addition, incidental learning, because it is based on a communicative need, is especially suited for helping learners understand and use words in real life situations. However, incidental learning alone may not provide enough exposures in a reasonable amount of time to facilitate the acquisition of the large number of words that learners need. Nation (2001) briefly reviews a number of studies and found that between five and twenty encounters with a word are necessary for vocabulary learning to take place. Therefore, for incidental learning to be effective, a word must be encountered in a communicative context multiple times. In addition, the learner must be able to understand the word's meaning from the context in which it is encountered. These requirements illustrate how the number of new words that a learner can acquire through incidental learning is determined by the amount of access and exposure they have to new vocabulary in the requisite kind of communicative context. By providing repeated exposure to new words and their meanings without relying on a communicative context to convey word-meaning, intentional learning has the potential to greatly speed up the rate at which learners can build their vocabularies.

Although incidental learning may be especially beneficial for learning certain aspects of word knowledge like collocation and intuitions of frequency (Schmitt, 2008), it is not always possible for a learner to initially grasp the meaning of an unknown word from the context in which it appears. If a learner's lexical coverage of a text is less than $98 \%$, they may not be able to understand enough of the context to be able to pick up the 
meaning of a particular unknown word (Laufer, 2005). Furthermore, uptake may be hindered for words whose meanings are too easily understood from context because a learner may not focus sufficiently on these words as they focus on the overall meaning of a text (Laufer). Unlike incidental learning, intentional learning does not rely on a communicative context to facilitate an initial understanding of meaning or uptake. Therefore, its effectiveness cannot be compromised by a context that causes a word's meaning to be too difficult or too easy to understand as may happen in incidental learning.

In addition, there is some research which indicates that intentional vocabulary learning, at least in some contexts, may lead to more word retention than incidental vocabulary learning. Laufer (2005) reviewed a number of studies that featured incidental and intentional learning to varying degrees. She found that an explicit, and more intentional, focus on vocabulary words seemed to be more successful across the studies. In addition, Laufer observed that the use of bilingual vocabulary lists seemed to correlate with an especially high degree of word retention.

This study focuses on intentional vocabulary learning and assumes the perspective that, although incidental vocabulary learning is valuable, intentional vocabulary learning is an effective and necessary part of how learners can build sufficiently large lexicons in reasonable amounts of time. A large number of word families must be acquired for a learner to carry out communicative tasks in English, and there are limits to how well purely incidental vocabulary learning can do this in a reasonable amount of time. For this reason, and because of the effectiveness of intentional vocabulary learning, it is worth 
investigating how intentional vocabulary learning integrates unfamiliar words into the mental lexicon.

\section{Organization of the Mental Lexicon}

When a word is learned, it becomes part of the mental lexicon, and to be a functional part of the mental lexicon the form, meaning, and use aspects of word knowledge must be acquired. An understanding of the lexicon shows how its organization correlates not just with our ability to communicate, but with our experience and knowledge of the world.

Aitchison (2003) described the mental lexicon as being organized into two components that pertain to 1) meaning and word class (lemmas), and 2) form. She posited that both the lemma and the form component of the lexicon house items that cluster, or form connections (some stronger than others), with other items based on semantic or formal characteristics, respectively. When a word is needed for production, two things must happen. First, an appropriate meaning must be selected, and then that meaning must be matched to an appropriate form. When a word is heard, its phonetic form must be identified and then matched to an appropriate meaning. When either of these processes happens, a number of possible words with strong connections (that cluster together in a semantic field) are activated prior to one being selected. The errors that individuals may make when speaking offer evidence for the way in which words cluster or form connections in the lexicon. An example of an interference error by a word related to the target word through meaning is, "The white (black) sheep of the family.", while an example of an interference error related to form is "A reciprocal 
(rhetorical) question" (Aichison, p. 220). It is also possible for this type of interference in production to be related to both form and meaning as in "You're a destructive (disruptive) influence" (Aitchson, p. 220).

Aitchison posits that the lexicon is comprised not just of connections between words, but also of connections that extend to memory and our general knowledge of the world. Because the organization of words in the lexicon connects with memory and general knowledge, it is "impossible to say where the 'meaning' of a word ends and general knowledge begins" (Aitchison, p. 244). In this way, when new words are integrated into an individual's lexicon they become part of a network that reflects how that individual experiences the world.

It is the lexicon and its connections between lexical items that allow us to use words in communicative contexts to both interpret and convey messages in a way that reflects our individual experience of the world. When different aspects of word knowledge are mastered, they are effectively integrated into the mental lexicon. The following section looks at how different approaches to vocabulary learning may affect how new words are initially integrated into the lexicon.

\section{Vocabulary Learning Strategies}

Different approaches to vocabulary learning may be beneficial for integrating different aspects of word knowledge into the lexicon. Schmitt and Schmitt (1993) observed that finding a principled way to evaluate the value of a given learning strategy could be very useful to teachers who cannot or may not be able to "personally tailor a strategy program for each individual group of students" (p. 31). Schmitt and Schmitt 
collected a number of vocabulary strategies from a variety of sources. They organized these strategies into two categories: strategies for initially discovering a word's meaning, and strategies for practicing a word's meaning after it is initially understood. They proposed that Craik's Levels of Processing Model (Craik \& Lockhart, 1972; Craik \& Tulving, 1975) may offer one way to analyze the effectiveness of vocabulary learning strategies. Schmitt and Schmitt offered a concise explanation of Craik's complex Levels of Processing Model:

Greatly simplified, the model states that the quality of learning directly depends upon how involved the mental manipulation of the new information is. If new material is given to a learner and it is only superficially processed, even for a considerable length of time, it is unlikely to become embedded in the mind and may be easily forgotten. Conversely, if the new material has to be analyzed, synthesized, and reworked, or associated with other already-known information, the processing will be more involved (deeper), giving the new material a better chance to become integrated with existing knowledge in the learner's mind. (p. 31)

Schmitt and Schmitt noted that some learning strategies intuitively seem to encourage deeper processing while others seem to favor relatively less processing, arguing:

Written and verbal repetition, use of word lists, and studying the part of speech of a word would intuitively involve relatively less processing, while the strategies involving association of new information with old, imaging, and manipulation of meaning imply the kind of mental activity that leads to deeper processing. (p. 31) 
It is also possible that, in line with Craik's model, a strategy that requires a specific type of involved manipulation may cause a word to be integrated into the lexicon in a specific way. For example, it is possible that a learning strategy that requires a learner to connect a word to a novel context or personal experience will cause the word to be integrated into the lexicon in relation to the specific connections generated through that strategy.

Schmitt and Schmitt found that, when surveyed, a group of learners indicated a preference for the strategies associated with more superficial processing, and did not favor those that Schmitt and Schmitt felt would encourage deeper processing. Schmitt and Schmitt did not deny the efficacy of the strategies that they felt pertained to more superficial processing, but questioned the extent to which these strategies alone could lead to more robust learning. For example, they noted that "word lists can be used to introduce learners to a large number of words in a short period of time. However, it is unlikely that they can lead to permanent learning by themselves" (p. 32). Schmitt and Schmitt went on to propose that "a combination of strategies, beginning with more superficial ones and leading to deeper ones, may promote the best balance between speed of learning and long term retention" (p. 32).

The present study investigated how learning through a vocabulary list may be supplemented through further mental manipulation and processing in the form of sentence writing, and investigated how this may affect how words are initially integrated into the lexicon. Sentence writing was chosen because it appears to be the type of activity that could elicit deeper processing. Schmitt and Schmitt identify sentence writing as an activity that that causes "manipulation of meaning", which they associate with deeper processing (p. 30). Additionally, sentence writing has the potential to 
encourage participants to connect words to a novel context or personal experience, which Schmitt and Schmitt also associate with deep processing. As mentioned above, strategies that encourage these types of connections during study might cause words to be integrated into the lexicon through the specific connections generated by that strategy.

\section{Word Associations Tests and the Lexicon}

When words have been learned, they become connected to other words in the lexicon. One way to investigate how words are integrated into the mental lexicon is through word association tests (WATs). WATs take a variety of forms, but some principles are common in all of them. In all WATs, an individual is presented with one or more cue-words, and is asked to produce one or more response words for each cueword. Although the exact wording of the instructions varies in different WATs, a participant is generally instructed to produce, either orally or in writing, the first word or words that immediately come to mind after they hear or read the cue-word.

Studies that use word associations to investigate the organization of the mental lexicon do so based on characteristics of the response-word that participants give during the WAT. Aitchison (2003) noted that WATs have indicated that words in the mental lexicon seem to cluster or have strong connections to other words from the same topic area or semantic field. For example, Aitchison noted that the stimulus word needle generally cued response words related to sewing like thread, pin(s), eye, or sew, but rarely elicited words for similarly thin pointy objects like nail or poker.

Traditionally, word association tests have been used to investigate the way words cluster and are organized in the lexicon by categorizing responses as either syntagmatic, 
paradigmatic, or clang responses, or as some variation of these three categories

(Fitzpatrick, 2006). The distinction between syntagmatic, paradigmatic, and clang word associations represents ways that words cluster, or are organized, in the lexicon. A syntagmatic association is one in which the cue-word and response word often appear in the same sentence or phrase, and a paradigmatic response is one in which the cue-word and the response word are from the same grammatical class and share similar meanings (Fitzpatrick, 2006). For example, a syntagmatic response to the cue-word $d o g$ could be house, or tired, whereas a paradigmatic response to the same cue-word could be cat, or canine. A clang response is one in which the response-word and the cue-word share similar phonological features. An example of a clang response to the cue-word $d o g$ could be $\log$.

Early word association studies with second language learners seemed to indicate that while native speakers (NSs) favored paradigmatic responses that were relatively homogenous, non-native speakers (NNSs) tended to produce fewer homogenous responses and produced a greater number of clang responses (Meara, 1982). Meara posited that these findings indicated that the semantic links between specific words are less strong in NNSs' lexicons than they are in those of NSs. More recently, Zareva (2007) found that NNSs produced no clang responses for familiar words, indicating that it is a lack of familiarity with a word rather than a weak semantic link between words that may cause clang responses. Fitzpatrick (2006) reported that past studies have indicated that NNSs, as their proficiency increases, move from producing more syntagmatic responses to favoring paradigmatic responses as native speakers have been reported to do. Zareva (2007), however, found no significant difference between the number of 
syntagmatic and paradigmatic responses that NSs and NNSs produced, and concluded that "learners who have reached an intermediate proficiency level already have lexicons structured along predominantly paradigmatic lines" (p. 148). Supporting Zareva's finding, Yuping (2010) found that participants of varying proficiencies tended to favor paradigmatic over syntagmatic responses.

Like the present study, Fitzpatrick $(2006,2011)$ chose not to use the traditional syntagmatic, paradigmatic, and clang categories. The categories used in the present study were adapted from those in Fitzpatrick (2011), which themselves were influenced by the categories in Fitzpatrick (2006). Fitzpatrick (2006) argued that the traditional syntagmatic, paradigmatic, and clang classification system may not be nuanced enough to accurately capture patterns that may exist in word association responses. Therefore, the traditional classifications may miss important information about how the lexicon is organized. To address this problem, Fitzpatrick (2006) developed a more nuanced classification system. The classification system used in Fitzpatrick (2006) included four main categories to classify WAT responses: meaning-based association, position-based association, form-based association, and erratic association. The above categories were further divided into a number of subcategories to create a more nuanced classification system than was provided by the traditional syntagmatic, paradigmatic, and clang categories. As an example, Fitzpatrick's meaning-based subcategories are displayed in Table 2.2 below (Fitzpatrick, 2006, p. 131). Although Fitzpatrick's categories differ from those that had been used in previous studies, Fitzpatrick's categories can still be related to the distinctions intended by the syntagmatic, paradigmatic, and clang categories. Fitzpatrick's (2006) meaning-based and position-based categories are roughly 
related to the paradigmatic and syntagmatic categories, respectively, and her form-based category is related to the clang category. Fitzpatrick's erratic association category captures WAT responses that do not fit into any of the other categories or which were based on a misunderstanding of the cue-word.

Table 2.2: Fitzpatrick's (2006) Word Association Meaning-Based Subcategories

\begin{tabular}{|lll|}
\hline category & subcategory & definition \\
\hline $\begin{array}{l}\text { meaning-based } \\
\text { association }\end{array}$ & defining synonym & x means the same as $\mathrm{y}$ \\
\cline { 2 - 3 } & specific synonym & $\begin{array}{l}\mathrm{x} \text { can mean y in some specific } \\
\text { contexts }\end{array}$ \\
\cline { 2 - 3 } & $\begin{array}{l}\text { hierarchical/lexical set } \\
\text { relationship }\end{array}$ & $\begin{array}{l}\mathrm{x} \text { and } \mathrm{y} \text { are in the same lexical set } \\
\text { or are coordinates or have a } \\
\text { meronymous or superordinate } \\
\text { relationship }\end{array}$ \\
\cline { 2 - 3 } & $\begin{array}{l}\text { quality association } \\
\text { of y quality of } \mathrm{x} \text { or } \mathrm{x} \text { is a quality }\end{array}$ \\
\cline { 2 - 3 } & context association & $\mathrm{y}$ gives a conceptual context for $\mathrm{x}$ \\
\hline conceptual association & $\begin{array}{l}\mathrm{x} \text { and y have some other } \\
\text { conceptual link }\end{array}$ \\
\hline
\end{tabular}

Using her new classification system, Fitzpatrick (2006) found that NNSs heavily favored meaning-based associations. The next highest category of responses was position-based associations, closely followed by form-based associations. Within the meaning-based association category, the NNSs favored responses in the following order: defining synonym, conceptual association, specific synonym, hierarchical/lexical set, context association, and quality association. 
Fitzpatrick and Izura (2011) developed another new WAT classification system (p. 384) (see Table 2.3) to investigate WAT associations with characteristics that could have pertained to more than one of Fitzpatrick's (2006) main categories (meaning-based, position-based, and form-based). The categories used in Fitzpatrick and Izura were form and meaning, meaning and collocation, collocation, form, equivalent meaning, and nonequivalent meaning. Fitzpatrick and Izura's examples of word associations for these categories as well as their descriptions are given in Table 2.3. The form and meaning, and meaning and collocation categories captured WAT responses that contained features pertaining to more than one of the main categories from Fitzpatrick (2006). Although Fitzpatrick and Izura's categories lack the subcategories of Fitzpatrick (2006), they are still able to capture differences between meaning-specific WAT responses through the two meaning-specific categories (equivalent meaning and nonequivalent meaning). The equivalent meaning category captured responses related to the cue-word through synonymy, coordination, and superordination while the nonequivalent meaning category captured responses "whose meaning is related but not equivalent to the cue word" (Fitzpatrick \& Izura, p.384).

Fitzpatrick and Izura (2011) found that the participants produced more nonequivalent meaning responses than any other response type for both L2 and L1 cue-words while the smallest number of responses pertained to the form category. Although more nonequivalent meaning responses were produced for both the L1 and L2 words, a greater number of nonequivalent meaning responses were produced for the L1 words than for the L2 words. The present study employed Fitzpatrick and Izura's equivalent meaning and 
nonequivalent meaning categories in the classification system used to analyze the WAT responses.

Table 2.3: Fitzpatrick and Izura's (2011) Word Association Categories

\begin{tabular}{|c|c|c|}
\hline category & description & examples \\
\hline form and meaning & $\begin{array}{l}\text { associative responses } \\
\text { related to the cue word in } \\
\text { both their form and general } \\
\text { meaning }\end{array}$ & $\begin{array}{l}\text { newsagent - newspaper } \\
\text { hairdresser - hairdryer } \\
\text { milkman - milk }\end{array}$ \\
\hline meaning and collocation & $\begin{array}{l}\text { associative responses } \\
\text { related to the cue word in } \\
\text { both general meaning and } \\
\text { in their tendency to co- } \\
\text { occur in the language }\end{array}$ & $\begin{array}{l}\text { rubbish - bin } \\
\text { peacock - feather } \\
\text { pearl - necklace } \\
\text { brother - sister }\end{array}$ \\
\hline collocation & $\begin{array}{l}\text { associative responses } \\
\text { whose only relation to the } \\
\text { cue word is their tendency } \\
\text { to co-occur in language }\end{array}$ & $\begin{array}{l}\text { captain - sparrow (film } \\
\text { character) } \\
\text { bat - man } \\
\text { goose - bump }\end{array}$ \\
\hline form & $\begin{array}{l}\text { associative responses } \\
\text { related to the cue word } \\
\text { only in their form }\end{array}$ & $\begin{array}{l}\text { mustard - mustang } \\
\text { lark - large }\end{array}$ \\
\hline equivalent meaning & $\begin{array}{l}\text { associative responses } \\
\text { whose meaning is } \\
\text { equivalent to the meaning } \\
\text { of the cue word (e.g., } \\
\text { related by synonymy, } \\
\text { coordination, or } \\
\text { superordination) }\end{array}$ & $\begin{array}{l}\text { sofa - couch } \\
\text { kitten - cat } \\
\text { parent - father } \\
\text { prince - king }\end{array}$ \\
\hline nonequivalent meaning & $\begin{array}{l}\text { associative responses } \\
\text { whose meaning is related } \\
\text { but not equivalent to the } \\
\text { cue word }\end{array}$ & $\begin{array}{l}\text { party - celebrate } \\
\text { accountant - number } \\
\text { ballgown - graduation }\end{array}$ \\
\hline
\end{tabular}


Word association tests and the developing lexicon. Most past studies that

investigated the L2 lexicon through word association tests used high frequency words and were not especially concerned with the extent to which the participants already knew or did not know them. An early study that investigated how learners responded to unfamiliar words was Beck (1981). Beck found that L2 learners produced significantly more meaning-based and position-based responses to taught words than to untaught words.

More recently, Yuping (2010) investigated how low-frequency and potentially unknown words are integrated into the lexicon. Yuping investigated the word associations learners of varying proficiencies made for both familiar and unfamiliar cuewords. Yuping conducted two experiments that used WATs: one that used highfrequency words and one that used low-frequency words. Yuping found that the lowfrequency words, which were tested 3 times, spaced a month and a half apart, elicited a large number of clang responses, and that these clang responses decreased with each subsequent test. The high-frequency words, which were tested only once across a range of proficiency levels, did not elicit many clang responses regardless of proficiency level. Additionally, clang responses did decrease for the low-frequency words as the participants' proficiency level increased. Interestingly, in the subsequent WATs with the low-frequency words, although most of the responses that changed moved from clang to paradigmatic or syntagmatic responses, there were instances where paradigmatic and syntagmatic responses changed to clang ones. Yuping asserted that this backsliding "proves Meara's view that the L2 mental lexicon is in a state of flux" (p. 81). Yuping also found that for both high-frequency and low-frequency words, the participants 
favored paradigmatic responses over syntagmatic responses. This finding may indicate that learners' lexicons may tend toward organization along paradigmatic rather than syntagmatic lines regardless of proficiency level or whether or not the words in question are familiar or unfamiliar.

\section{Study Motivation and Research Questions}

Study Motivation. Most studies that have used WATs featured words that were already known to the participants. This current study, however, investigated how newly studied words are integrated into the lexicon by introducing entirely unknown stimulus words to the participants immediately prior to the WAT. Beck (1981) used WATs to investigate how unfamiliar words were integrated into the lexicon over time before and after they were encountered in the regular course of classroom instruction. Yuping (2010) used WATs to investigate how unfamiliar words were integrated into the mental lexicon over time as well although whether or not the words were studied, and to what extent, is unclear. Neither Beck nor Yuping specifically investigated the way that new words are integrated into the lexicon in the earliest stages of the learning process through intentional learning. To address this gap, this study used a WAT to investigate how previously unknown words may be integrated into the lexicon during the earliest stage of the vocabulary learning process through intentional learning. In addition, the WAT responses were classified using categories adapted from Fitzpatrick and Izura (2011), which are better suited to capturing subtle differences between responses than the classification strategies used by Beck and Yuping. This novel application of the WAT format is the first time a WAT has been used to investigate how new vocabulary is 
integrated into the lexicon through intentional learning immediately after new words are studied for the first time. Finally, the present study investigated how a sentence writing task, designed to elicit a deeper focus on meaning during intentional learning, affected the way the new words were being integrated into the lexicon.

\section{Research questions:}

1. What patterns of word associations do learners show for newly introduced vocabulary words after completing a sentence writing task with those words?

2. How do those word association patterns compare to those of learners who did not complete the sentence writing task?

3. How do the word association patterns for the newly introduced vocabulary words compare to word association patterns for well-known words. 


\section{Chapter Three}

\section{Methods}

The unit of measurement used in this experimental study was the responses to the word association test (WAT) that the participants produced. The study had two independent variables and one dependent variable. The independent variables were whether a WAT response was cued by a high or low-frequency stimulus word (wordfrequency), and whether a WAT response was given by a participant in the control group or the treatment group (group). The dependent variable was the category into which the WAT responses were classified (response type).

\section{Participants}

The participants in the study were 16 volunteers (eight women and ten men) who were enrolled in Portland State University's Intensive English Language Program (IELP). The participants were all enrolled in either an IELP level 4 or 5 (high-intermediate to advanced) class. The average age of the participants was 31. They ranged in age from 20 to 59 although the majority were in their early twenties to mid-thirties. The time they had been in the US ranged from one to 33 months. Eight of the participants were assigned to the control group and eight were assigned to the treatment group. The participants were from Japan, Saudi Arabia, Tajikistan, Iraq, China, South Korea, and Kuwait and, between them, eight languages were represented. 


\section{Apparatus and Materials}

Word association test word selection. Ten low-frequency words and ten highfrequency words were selected to be cue-words for the WAT (see Table 3.1). To ensure that difference in word class would not be an extraneous variable, words from only one word class, nouns, were selected to be used in this study.

Because it was important that the participants not already know the low-frequency cue-words, these words were selected from the 12th to 14 th 1000 most frequent word families from the British National Corpus (BNC). These BNC words were selected from the 14,000 BNC word list included in Nation's (n.d.) Range program. Half of the lowfrequency words were concrete nouns and half were abstract nouns. An equal number of concrete and abstract nouns were selected to negate any effect that a majority of either could have on the WAT results for the low-frequency words.

The ten high-frequency words all came from within the first 150 words of the General Service Word List (Bauman \& Culligan, 1995) in order to ensure that they would be known to the participants. Because the participants were advanced students, it was assumed that they would know the words selected from this section of the General Service Word List. 
Table 3.1: High and Low-Frequency WAT Cue-Words

\begin{tabular}{|c|c|}
\hline high-frequency words & low-frequency words \\
\hline day & atoll \\
hand & coven \\
house & fealty \\
life & guile \\
man & hubris \\
number & malady \\
people & sojourn \\
school & trill \\
work & plankton \\
world & refectory \\
\hline
\end{tabular}

Vocabulary knowledge scale. At the beginning of the study, the participants completed a vocabulary knowledge scale (VKS) (Paribakht \& Wesche, 1993) to rate the extent to which they were familiar with the ten low-frequency words (see Appendix A). The original VKS, developed by Paribakht and Wesche, asked participants to choose one out of five options that represented the extent to which they knew a word. I chose to only use the first four options on the scale because they were sufficient to capture the necessary information about the participants' word knowledge for the purposes of this study. The inclusion of the fifth option, which asked learners to use the word in a sentence, was not necessary because, for this study, it was only necessary to determine whether or not a participant could link a correct meaning to the words' forms 
The four VKS options, as they were presented with the word atoll, are:

\section{Atoll}

1) I have never seen this word before.

2) I have seen this word before, but I don't know what it means.

3) I have seen this word before and I think it means (synonym or translation).

4) I know this word. It means (synonym or translation).

The VKS indicated the extent, if any, to which the participants believed themselves to be familiar with the ten low-frequency words. Options 3) and 4) asked learners to provide a synonym or translation for the word in question; thereby helping to expose inconsistencies between the words the participants reported knowing, and those they truly knew.

Although it was assumed that the participants knew the ten high-frequency words, they were included on the VKS, with one exception ${ }^{1}$, to help to assess the reliability of participants' VKS responses for the low-frequency words. If a participant had reported not knowing a number of the high-frequency words, it could have been an indication that the participants might have underreported their knowledge of the low-frequency words as well.

Intentional vocabulary learning period. After completing the VKS, each participant spent 20 minutes working with the low-frequency words. During this 20 minute intentional learning period, each participant was provided with the low-frequency 1. On the VKS, the high-frequency word year replaced the word world, which appeared on the WAT. 
words' definitions so that they could discover and learn their meanings. Both the control and treatment group were given two sheets of paper to use if desired and a pencil or pen if they didn't have one of their own. These papers were collected at the end of the intentional learning period if a participant had opted to use them.

At the beginning of the intentional vocabulary learning period, the participants assigned to the treatment group were given a worksheet that instructed them to write one or two sentences with each of the low-frequency words (see Appendix B). The instructions asked participants to write sentences that used the words in a meaningful way. In addition to intending to elicit deeper processing, the sentence writing activity required the production of a physical artifact (written sentences), which made it possible to confirm that the experimental group was using the strategy as instructed.

The control group was simply instructed to use the twenty minutes to do their best to learn the words. In the past, these instructions have been used to investigate how the effects of not assigning a vocabulary strategy compare to the effects that specific strategies have on learning (Barcroft, 2002; Desrochers, Wieland, \& Cote, 1991). In the present study, these instructions were intended to allow the participants in the control group to study the words as they would normally study vocabulary thereby creating a somewhat natural study condition to compare to the experimental condition. However, the extent to which the control group's study condition can be said to truly reflect what they normally would do to learn vocabulary is limited because the participants could not control the way they discovered the words' meanings, the amount of time they would study, or the materials they could use while studying. 
Low-frequency word definitions. After the VKS, but prior to the WAT, participants in both the treatment and the control group worked with the ten lowfrequency words for 20 minutes. Participants in both the control and treatment group were given ten five inch by eight inch index cards. Each card featured one of the ten target vocabulary words and contained information, printed on the card's face, that the participants could use to use to initially discover each word's meaning. This information was the dictionary entry for that word reproduced from an advanced learner dictionary (Longman, 2004) (see table 3.2). Because of the relative simplicity of the dictionary definitions and the participants' high class levels, it was assumed that they would be comfortable using the definitions to discover the low-frequency words' meanings. 
Table 3.2 Low-Frequency Word Definitions

\begin{tabular}{|c|c|}
\hline $\operatorname{atoll}(\mathrm{N})$ : & a coral island in the shape of a ring. \\
\hline $\operatorname{coven}(\mathrm{N})$ : & a group or meeting of witches \\
\hline fealty $(\mathrm{N})$ : & loyalty to a king, queen etc \\
\hline guile $(\mathrm{N})$ : & $\begin{array}{l}\text { the use of clever but dishonest methods to deceive someone: with a } \\
\text { little guile she might get what she wanted. }\end{array}$ \\
\hline hubris $(\mathrm{N})$ : & to much pride \\
\hline malady $(\mathrm{N}):$ & a serious problems in society \\
\hline sojourn $(\mathrm{N})$ : & $\begin{array}{l}\text { a short period of time that you stay in a place that is not your } \\
\text { home: a brief sojourn in Europe }\end{array}$ \\
\hline $\operatorname{trill}(\mathrm{N})$ : & a short repeated high sound: the trill of blackbirds. \\
\hline plankton $(\mathrm{N})$ : & $\begin{array}{l}\text { the very small forms of plant and animal life that live in water, } \\
\text { especially in the sea, and are eaten by fish }\end{array}$ \\
\hline refectory $(\mathrm{N})$ : & $\begin{array}{l}\text { a large room in a school, college, etc. where meals are served and } \\
\text { eaten }\end{array}$ \\
\hline
\end{tabular}

Word association test. The intentional learning period was immediately followed by the word association test (WAT). Each participant was asked to produce a response word for each cue-word. Each cue-word was spoken for the participant to hear and, at the same time, the word was held up on a 5 inch by 8 inch index card for them to see. The participants were instructed to say the very first word that entered their head when presented with the cue-word. They were told not to think about their responses, and to be spontaneous. Before beginning the WAT in earnest, the participants were given 
between two and ten practice words to ensure that they understood how the word association test worked. The exact number of practice words given to each participant was determined based on the amount of practice that seemed necessary for them to understand the task. The participants were given practice words until they appeared able to produce response words to the practice cue-words without hesitation.

For cue-words, the WAT included the ten low-frequency words that the participants had been studying in the previous intentional vocabulary learning period as well as the additional high-frequency and presumably familiar words mentioned earlier. The cue-words were presented to each participant in the same order-alternating between high and low-frequency. The high-frequency cue-words provided WAT responses that could be compared to those elicited by the low-frequency words. In addition, the highfrequency cue-words served as distractors to make the participants less likely to provide non-spontaneous responses when they realized that a high proportion of the cue-words were those that they had just studied during the intentional learning task.

Post-WAT Debriefing. Immediately following the WAT, each participant was asked what they did to learn the words, and what they thought about when they were learning the words. These questions gathered information about the intentional learning techniques employed by the control group as well as any techniques, apart from the sentence writing activity that the treatment group may have used. The interview also had the potential to indicate whether or not participants in the control group may have spontaneously engaged in a learning strategy that had characteristics similar to the treatment task. 


\section{Procedures}

Each participant scheduled a separate time to take part in the study as the WAT was administered individually and directly followed the intentional learning period. The participants were assigned to either the control or treatment group based on the order in which they took part in the study. The first participant was assigned to the treatment group and the second was assigned to the control group. The assignment to groups continued to alternate in this way.

After reviewing and signing an informed consent form, the participants completed a short demographic information form (see Appendix C and D, respectively). Next, the participants completed the VKS to determine whether they had any prior knowledge of the ten low-frequency target words featured in the experiment. After the VKS, the participants were asked to learn the ten low-frequency vocabulary words as described above. Immediately after this intentional learning period, all the participants took part in the WAT. Immediately after the WAT, each participant was asked two questions about their experience during the intentional learning task. The participants were asked what they did to learn the words and what they were thinking about while they were learning the words. Some participants were asked additional questions in response to their answers to the two questions above.

\section{Analysis}

Word classification. Initially, the word association responses the participants produced during the WAT were categorized using a modified version of the categories 
from Fitzpatrick and Izura (2011). The categories from Fitzpatrick and Izura (form and meaning, meaning and collocation, collocation, form, equivalent meaning, and nonequivalent meaning) were initially chosen because they captured some subtle differences between the WAT responses that may have escaped the traditional syntagmatic, paradigmatic, or clang categories that have often been used in the past. However, as there were few form and meaning and meaning and collocation responses in my data, the system was simplified into four categories with two subcategories (see Table 3.3). The four main categories that I used to classify the responses were meaning, form, position, and other. Examples of word associations for these categories are given in Table 3.3. Fitzpatrick's collocation category was changed to the position category in order to make it clear that, in this study, the category in question could capture responses connected to the cue-words through syntactic as well collocational co-occurrence.

The form category was used for associations that shared only a phonetic or orthographic similarity to the cue-word. For example, the association tool for the cueword atoll was classified as pertaining to the form category because they are phonetically similar.

The position category was used for responses that co-occurred in a syntactic or collocational setting with the cue-word. For example, the association place for the cueword work was classified as position because it collocates with the cue-word as work place. 
Table 3.3: Word Association Response Categories

\begin{tabular}{|c|c|c|c|}
\hline main categories & subcategories & description & examples \\
\hline form & & $\begin{array}{l}\text { responses related to the cue } \\
\text { word through form }\end{array}$ & $\begin{array}{l}\text { atoll - tool } \\
\text { guile - guilt }\end{array}$ \\
\hline position & & $\begin{array}{l}\text { responses related to the cue- } \\
\text { word through syntactical and } \\
\text { collocational co-occurrence }\end{array}$ & $\begin{array}{l}\text { work - place } \\
\text { school - elementary }\end{array}$ \\
\hline \multirow[t]{2}{*}{ meaning: } & $\begin{array}{l}\text { equivalent } \\
\text { meaning }\end{array}$ & $\begin{array}{l}\text { responses related to the cue- } \\
\text { word through synonymy, } \\
\text { coordination, or } \\
\text { superordination }\end{array}$ & $\begin{array}{l}\text { hand - fist } \\
\text { atoll - island }\end{array}$ \\
\hline & $\begin{array}{l}\text { nonequivalent } \\
\text { meaning }\end{array}$ & $\begin{array}{l}\text { responses related to the cue- } \\
\text { word through meaning, but } \\
\text { not through synonymy, } \\
\text { coordination, or } \\
\text { superordination. }\end{array}$ & $\begin{array}{l}\text { refectory - food } \\
\text { fealty - queen }\end{array}$ \\
\hline other & & $\begin{array}{l}\text { responses with no apparent } \\
\text { connection to the cue-word } \\
\text { and responses that could not } \\
\text { be understood on recording }\end{array}$ & $\begin{array}{l}\text { day - watch } \\
\text { malady - car }\end{array}$ \\
\hline
\end{tabular}

The meaning category captured all the WAT responses connected to the cue-word through meaning. For example, the association fist for the cue-word hand was classified as pertaining to the meaning category because they share a meaning-based connection.

The other category was used for erratic responses where it was not possible to say with any degree of certainty what type of connection, if any, was present as well as for responses that could not be understood clearly on the WAT recording. An example of an erratic other association was the response word car for the cue-word malady.

In addition, Fitzpatrick and Izura's (2011) equivalent meaning and nonequivalent meaning categories were used as subcategories of the meaning category. All the meaning 
responses were assigned to one of the two meaning-specific subcategories: equivalent meaning and nonequivalent meaning. These subcategories captured differences in the type of meaning-based responses. Any responses that were related to the cue word through synonymy, coordination, or superordination were included in the equivalent meaning category. Additionally, the equivalent meaning category was used to capture responses that, even if not strictly related to the cue-word through synonymy, coordination, and superordination, could be substituted for them in a significant number of contexts and that bore a close, even if not synonymous, meaning relationship to them. Under this criteria antonyms, and some holonyms and meronyms could be assigned to the equivalent meaning category. Two examples of equivalent meaning responses are the association fist for the cue-word hand and the association island for the cue-word atoll. In some cases, response words that weren't nouns, but were closely related to nouns that would have been classified as equivalent meaning associations, were themselves assigned to the equivalent meaning category. For example, the association dead for the cue word life was classified as equivalent meaning and the association proud for the cue-word hubris was also classified as equivalent meaning. The nonequivalent meaning category was used for all responses that did not have an equivalent meaning connection to the cue word, but still shared an obvious meaning based connection. For example, the response food for the cue word refectory is a nonequivalent meaning response because there is a clear meaning based connection, but it is not through an equivalent meaning-based connection.

After both the control and treatment groups' responses were coded, the responses in each category were tallied based on frequency. The WAT data was then analyzed 
using a loglinear analysis. A loglinear analysis was chosen because it is able to test for significant interactions between three categorical variables, which in this study were word-frequency, group, and WAT response type. A Post-hoc Pearson's chi-square test, which tests for interactions between two categorical variables, was then used to reveal more information about significant interactions indicated by the loglinear analysis where more detail was needed. 


\section{Chapter Four}

\section{Results}

In this section, I present the results for each portion of the experiment. First, I will present the results of the Vocabulary Knowledge Scale (VKS), which confirmed whether or not participants knew the meaning of any of the low-frequency words that were used in the word association test (WAT). Following the section on the VKS, I will present the WAT results. The section on the WAT results will go over both the categorization of WAT responses as well as the results of the statistical analysis performed on the final WAT response categories. Finally, I will talk about what was revealed by the notes some control participants took during the intentional learning period as well as what was revealed by the control participants' responses during the post-WAT debriefing

\section{Vocabulary Knowledge Scale}

Table 4.1 displays the number of instances in which the participants indicated knowledge of either a high or low-frequency word by marking either option 3 or 4 on the VKS. A ranking of 3 was attached to the statement I have seen this word before and I

think it means (synonym or translation). A ranking of 4 was attached to the statement I know this word. It means (synonym of translation). Table 4.1 also displays the number of times rankings of 3 or 4 for the low-frequency words corresponded with written responses demonstrating knowledge of the word in question. 
Table 4.1: VKS Instances of Self-Reported Understanding of Meaning*

\begin{tabular}{|lll|ll|}
\hline $\begin{array}{l}\text { low-frequency } \\
\text { words }\end{array}$ & $\begin{array}{l}\text { instances of } \\
\text { VKS rankings } \\
\text { of 3 or 4 }\end{array}$ & $\begin{array}{l}\text { instances } \\
\text { where written } \\
\text { VKS response } \\
\text { indicated } \\
\text { understanding }\end{array}$ & $\begin{array}{l}\text { high-frequency } \\
\text { words }\end{array}$ & $\begin{array}{l}\text { Instances of } \\
\text { VKS rankings } \\
\text { of 3 or } 4\end{array}$ \\
\hline atoll & 2 & 0 & day & 16 \\
coven & 2 & 0 & hand & 16 \\
fealty & 1 & 0 & house & 16 \\
guile & 1 & 0 & life & 16 \\
hubris & 0 & 0 & man & 16 \\
malady & 1 & 0 & number & 16 \\
sojourn & 1 & 0 & people & 16 \\
trill & 3 & 0 & school & 16 \\
plankton & 5 & 4 & yeark & 16 \\
refectory & 4 & 0 & 16
\end{tabular}

"The maximum possible in each column is 16-the total number of participants.

The results of the VKS indicated that, for the most part, the participants did not know the low-frequency words. Although there were 20 instances where participants indicated that they knew, or thought they knew, low-frequency words, in all but four of these cases the written information that the participants provided on the VKS demonstrated that they did not truly know the meanings of the words in questions. For example, one participant indicated that they knew the meaning of the word refectory by writing recycling--a response that showed they did not know the meaning of refectory.

Four participants did demonstrate knowledge of the meaning of the word plankton on the VKS. In addition, one participant indicated knowledge of plankton in 
conversation following the WAT. As a result, the five WAT responses provided by these participants for plankton were excluded from the WAT analysis ( 3 from the control group and 2 from the treatment group).

While all participants indicated they knew the high-frequency words, four participants provided one or two synonyms or definitions for these words that did not make sense. Because of the participants' high IELP class-level, I assumed that these responses indicated a difficulty communicating knowledge of the word rather than a lack of understanding of the high-frequency word itself. Additionally, four participants wrote definitions or synonyms for the high-frequency words in their native languages whose correctness I could not confirm. Again, because of the participants' high IELP classlevel, it was reasonable to assume these high-frequency words were known to the participants without translating what they wrote for the VKS.

\section{Word Association Test}

The distribution of the WAT responses in the main word association response categories (form, position, meaning, and other) is displayed in Table 4.2 below. The distribution of the WAT responses in the meaning-specific subcategories (equivalent meaning and nonequivalent meaning) is displayed in Table 4.3.

Control group. Of the 160 WAT associations produced by the control group, three responses for the cue-word plankton were excluded from the analysis because the participants indicated prior knowledge of the cue-word's meaning. This left 80 responses to high-frequency words and 77 responses to low-frequency words from the control 
group. $86.2 \%$ of the control group's WAT responses to the high-frequency words were meaning associations. Within the meaning category, $66.7 \%$ of the responses to highfrequency words were equivalent meaning associations while $33.3 \%$ were nonequivalent meaning associations. For the low-frequency words, $80.5 \%$ of the responses were meaning associations. Of these, $59.7 \%$ were equivalent meaning associations and $40.3 \%$ were nonequivalent meaning associations. $3.7 \%$ of the control group's responses to the high-frequency words were form associations and $2.5 \%$ were position associations. For the low-frequency words, $65.2 \%$ of the responses were form associations and none were position associations. $7.5 \%$ of the control group's responses to high-frequency words and $14.3 \%$ of their responses to low-frequency words were classified as other associations.

Treatment group. Of the 160 WAT associations produced by the treatment group, two responses for the cue-word plankton were excluded from the analysis because the participants indicated prior knowledge of the cue-word's meaning. This left 80 responses to high-frequency words and 78 responses to low-frequency words. Like the control group, a high number of the treatment group's WAT responses were classified as meaning associations with the majority of these being equivalent meaning associations. For the high-frequency words, $88.7 \%$ of the treatment group's responses were meaning associations. Of these, $76.1 \%$ were equivalent meaning associations and $23.9 \%$ were nonequivalent meaning associations. For the low frequency words, $44.9 \%$ of the treatment group's responses were meaning associations. Of these, $62.9 \%$ were classified as equivalent meaning associations and $37.1 \%$ were classified as nonequivalent meaning associations. $23.1 \%$ of the treatment group's WAT responses to the low-frequency words 
were form associations while none of their responses to the high-frequency words were.

$2.5 \%$ of the treatment group's responses for high-frequency words were position associations while none of the low-frequency responses were. $8.7 \%$ of the treatment group's responses to high-frequency words and $32.1 \%$ of their responses to lowfrequency words were classified as other associations.

Table 4.2: Distribution of WAT Responses in the Main Categories

\begin{tabular}{|l|c|c|c|c|c|}
\hline \multicolumn{1}{|c|}{ control } & form & position & meaning & other & total \\
\hline $\begin{array}{l}\text { high-frequency } \\
\text { words }\end{array}$ & $3(3.7 \%)$ & $2(2.5 \%)$ & $69(86.2 \%)$ & $6(7.5 \%)$ & $80(100 \%)$ \\
\hline $\begin{array}{l}\text { low-frequency } \\
\text { words }\end{array}$ & $4(5.2 \%)$ & 0 & $62(80.5 \%)$ & $11(14.29 \%)$ & $77(100 \%)$ \\
\hline \multicolumn{1}{|c|}{ treatment } \\
high-frequency \\
words \\
$\begin{array}{l}\text { low-frequency } \\
\text { words }\end{array}$
\end{tabular}

Table 4.3: Distribution of WAT Responses in the Meaning-Specific Subcategories

\begin{tabular}{|l|c|c|c|}
\hline \multicolumn{1}{|c|}{ control } & equivalent meaning & nonequivalent meaning & total \\
\hline $\begin{array}{l}\text { high-frequency } \\
\text { words }\end{array}$ & $46(66.7 \%)$ & $23(33.3)$ & $69(100 \%)$ \\
\hline $\begin{array}{l}\text { low-frequency } \\
\text { words }\end{array}$ & $37(59.7 \%)$ & $25(40.3 \%)$ & $62(100 \%)$ \\
\hline \multicolumn{1}{|c|}{ treatment } & equivalent meaning & nonequivalent meaning & total \\
\hline $\begin{array}{l}\text { high-frequency } \\
\text { words }\end{array}$ & $54(76.1 \%)$ & $17(23.9 \%)$ & $71(100 \%)$ \\
\hline $\begin{array}{l}\text { low-frequency } \\
\text { words }\end{array}$ & $22(62.9 \%))$ & $13(37.1 \%)$ & $35(100 \%)$ \\
\hline
\end{tabular}


Statistical analysis. After the WAT responses for each group were assigned to categories and tallied for frequency, a loglinear analysis was used to determine the statistical significance of differences in the patterning of the WAT responses for both the main categories and for the meaning specific subcategories. A post-hoc Pearson's chisquare test performed for the main categories provided more detailed information about the significant effects indicated in the loglinear analysis. The responses that had been classified as other associations were excluded from the analysis because it was not possible determine what relationship, if any, they had to the cue-words.

Because so few responses fell into the form and position main categories, these categories were combined into a single non-meaning category to better adhere to the assumptions of the loglinear analysis. The loglinear analysis requires that at least $80 \%$ of cells have expected frequencies of more than five and all cells have expected frequencies greater than one. Collapsing the form and position categories into a single non-meaning category raised the cell count to levels that met these assumptions. The distribution of the WAT responses in the meaning and non-meaning categories is displayed in Table 4.4 below. Combining the form and position categories into the single non-meaning category still allowed for an investigation of how the experimental condition (sentence writing) affected the development of meaning based connections in the lexicon. 
Table 4.4: Collapsed Main Categories: Meaning and Non-Meaning

\begin{tabular}{|c|c|c|c|}
\hline control & non-meaning & meaning & total \\
\hline high-frequency words & $5(6.7 \%)$ & $69(93.2 \%)$ & $74(100 \%)$ \\
\hline low-frequency words & $4(6.1 \%)$ & $62(93.9 \%)$ & $66(100)$ \\
\hline treatment & non-meaning & meaning & total \\
\hline high-frequency words & $2(2.74 \%)$ & $71(97.3 \%)$ & $73(100 \%)$ \\
\hline low-frequency words & $18(34 \%)$ & $35(66 \%)$ & $53(100 \%)$ \\
\hline
\end{tabular}

Main categories. The three-way loglinear analysis on the two main categories (meaning and non-meaning) generated a final model that kept all effects $\left(\mathrm{X}_{(0)}^{2}=0\right)$. The analysis indicated that the highest order interaction (group $\times$ word frequency $\times$ response category) was significant $\left(\mathrm{X}_{(1)}^{2}=9.61, p=.001\right)$. There was also a significant two-way interaction for response type $\times$ group $\left(\mathrm{X}_{(1)}^{2}=7.52, p=.006\right)$, which indicated a significant difference in the way the control and treatment group's WAT responses were distributed across the main categories. Additionally, there was a significant two-way interaction for response type $\times$ word frequency $\left(\mathrm{X}_{(4)}^{2}=14.38, p=.000\right)$, which indicated that word frequency had an effect on the type of WAT response produced. There was also a significant main effect for response type $\left(\mathrm{X}^{2}(7)=185.50, p=.000\right)$ showing that the higher proportion of meaning-based responses was statistically significant.

The planned comparisons using s Pearson's chi-square revealed more detail about the significant effects indicated by the loglinear analysis. The Pearson's chi-square revealed that there was no significant difference between the control group's responses to high and low-frequency words $\left(\mathrm{X}_{(1)}^{2}=.028, p=.867\right)$. However, it did reveal that the treatment group produced a significantly greater proportion of non-meaning responses for 
the low-frequency words than they produced for the high-frequency words $\left(\mathrm{X}^{2}{ }_{(1)}=\right.$ 22.417, $p=.000)$.

Subcategories. The three-way loglinear analysis of the meaning-specific subcategories (equivalent meaning and nonequivalent meaning) generated a final model that kept all effects $\left(\mathrm{X}_{(0)}^{2}=0\right)$. The analysis indicated that the highest order interaction $\left(\right.$ group $\times$ word frequency $\times$ response category) was not significant $\left(\mathrm{X}_{(1)}^{2}=.325, p=.57\right)$. An analysis of the two-way effects also revealed no significant interactions $\left(\mathrm{X}^{2}{ }_{(4)}=\right.$ $9.512, p=.05)$. These results indicate that group and word frequency did not affect the distribution of responses across the meaning-specific subcategories. However, the analysis did reveal a significant main effect between the meaning-specific subcategories $\left(\mathrm{X}^{2}{ }_{(7)}=48.248, p=.000\right)$, indicating that the higher proportion of equivalent meaning to nonequivalent meaning responses was statistically significant.

\section{Intentional Learning Period Study Notes and Post-WAT Debriefing}

For the debriefing that followed the word association test, all but two of the participants from the control group revealed that they had tried to associate the lowfrequency words to novel contexts and/or their personal experience. This connecting of the target words to existing knowledge of the world is similar to what the sentence writing task aimed to encourage in the treatment group. However, the study notes revealed that only two of the participants in the control group had written sentences with the words during the intentional learning period while several had rewritten the definitions or parts of the definitions. One of the control group participants who wrote 
sentences wrote approximately six sentences that used six of the words in novel ways. The other wrote only one true sentence that used the word in a novel context although this participant also wrote some novel sentence fragments as well as comments about some of the words' meanings which were similar to the definitions provided.

Although the majority of the participants in the control group worked to associate the target words to novel contexts, the vast majority did so in a way significantly different from the treatment group. While the treatment group was required to write a sentence for each low-frequency word, almost all the participants in the control group connected the new words to novel contexts and/or personal experiences exclusively in their minds. That so many of the control group did report that they worked to connect the new words to novel contexts and/or personal experience indicates the presence of some degree of deep processing. This finding may indicate that this deep processing vocabulary strategy is one that many learners favor without prompting.

\section{Summary of Results}

The VKS indicated that, for the most part, the participants did not know the meanings of the low-frequency words. In cases where the VKS indicated that a participant did know a low-frequency word's meaning, that participant's WAT response for that word was excluded from the WAT analysis. The majority of the WAT responses were meaning based, with the majority of these being equivalent meaning associations. Although there was not a significant difference between the control group's responses to the high and low-frequency words, the treatment group produced a significantly higher 
proportion of non-meaning responses to the low-frequency words than they did for the high-frequency words. 
Chapter Five

\section{Discussion and Conclusion}

In this section, I first discuss the findings of the analysis performed on the word association main categories (meaning and non-meaning) and on the meaning-specific subcategories (equivalent meaning and nonequivalent meaning). Following the discussion of the main categories and subcategories, I discuss some additional patterns that were observed in the word association test data. Finally, I discuss the implications of the present study for future research as well as for language teaching.

\section{Main Categories}

Both the control and treatment group heavily favored meaning-based responses relative to non-meaning-based responses for both the high and low-frequency words. These findings support Fitzpatrick (2006), who also found that L2 speakers favored meaning-based associations. Although Fitzpatrick and Izura (2011) had multiple meaning-based categories that corresponded to this study's main meaning category, when Fitzpatrick and Izura's multiple categories are combined, her results also show more meaning-based responses to L2 words were made than purely non-meaning responses.

To the extent that the meaning category in this study coincides with the paradigmatic category in previous studies, this study supports past findings that indicated that L2 speakers tended to produce more meaning-based (paradigmatic) responses than either clang (form-based) or syntagmatic (position-based) responses for familiar words (Zareva, 2007; Yuping, 2010) as also do speakers in their L1 (Meara, 1982; Zareva, 2007). 
The learners demonstrated strong meaning-based connections in the lexicon for the high-frequency words, which is not surprising because the participants knew those words well prior to their participation in the study. That the participants produced more meaning than non-meaning responses for the new, low-frequency words, however, indicates that they were generally successful at attaching meaning to the low-frequency words' forms during the intentional study period in a way that allowed them to access those connections during the word association test (WAT). Additionally, this result indicates that new vocabulary words may begin integration into the lexicon through meaning-based connections even in the earliest stages of the vocabulary learning process.

It is interesting that there was not a significant difference between the control group's responses to high and low-frequency words whereas, for the treatment group, there was. While still favoring meaning responses, the treatment group produced a greater proportion of non-meaning responses for the low-frequency words than they did for the high-frequency words. This higher proportion of non-meaning responses was the result of the higher number of form-based responses that the treatment group made for low-frequency words.

The sentence writing activity, done by the treatment group, was intended to be an activity that could provide a context favorable to deeper level processing (Craik \& Lockhart, 1972; Craik and Tulving, 1975). The levels of processing model predicts that deeper processing, in which new information is "analyzed, synthesized, and reworked, or associated with other already-known information" gives "the new material a better chance to become integrated with existing knowledge in the learners mind" (Schmitt and Schmitt, 1993, p. 31). 
The sentence writing task attempted to encourage this type of deeper processing by requiring the participants to connect the low-frequency words, and their meanings, to already known information through the production of novel sentences. As such, I predicted that it could have encouraged more meaning-based connections rather than form-based ones, which are associated with shallower levels of processing (Craik \& Tulving). Additionally, by requiring the words be fit into syntactic structures, the sentence writing task seemed like it could have led to more position-based responses. The data, however, reveal that few were produced by either group. While the sentence writing task did yield a majority of meaning-based responses for the treatment group, it also resulted in a higher percentage of non-meaning responses, all of which were also form-based, than were produced by the control group. As indicated by the post-WAT debriefings, the control group appears to have engaged with the words in a way conducive to deep processing as well. For this reason, differences between the treatment and control group's WAT responses cannot necessarily be taken as a comparison between the effects of shallow and deeper levels of processing. However, the increased percentage of non-meaning form-based responses in the sentence-writing condition may still indicate that deep processing might not have functioned as intended for the treatment group.

After the WAT responses had already been analyzed, I reviewed Barcroft (2004), who investigated the effect of sentence writing on the retention of new vocabulary. The increase of form based responses in the sentence writing condition seems to conform to Barcroft's finding that sentence writing led to a decrease in the retention of new words on productive knowledge post-tests. Barcroft speculated that the decrease in retention on the 
productive knowledge tests might indicate that sentence writing could have an inhibitory effect on word-form retention, rather than on the retention of word-meaning, in the early stages of vocabulary learning. The present study's WAT, unlike Barcroft's productive knowledge test, did not require the participants to produce the target words' forms. The WAT revealed a decrease in meaning-based lexical connections in the sentence writing condition. There is more than one possible reason why the sentence writing condition could have correlated with an increase in more non-meaning connections for lowfrequency words. First, deep processing, as facilitated through sentences writing, may not aid in the formation of meaning-based connections during the earliest stages of the learning-process. Alternately, it is possible that the sentence writing task simply failed to encourage this type of deeper processing.

It is possible that the sentence writing task led to a greater proportion of nonmeaning responses because it placed additional cognitive demands on the participants in the treatment group. An additional cognitive demand could have resulted from the treatment group having to expend additional mental energy on imagining a context in which to use the target words rather than just focusing on connecting them to the definitions provided. However, as mentioned above, the majority of the participants in the control group reported trying to connect the words to novel contexts and personal experience mentally, which indicates that this cognitive demand alone may not be sufficient to explain differences between the control and treatment group's WAT responses. An additional cognitive demand could have come from fitting the words into a syntactic structure as well as the mechanical act of writing itself, which may have caused participants in the treatment group to focus more on the word's form than they 
would have had they not been required to produce sentences. Additionally, the sentence writing task may have been more cognitively demanding because the participants may have been unaccustomed to using this type of activity in this early stage of the vocabulary learning process. Finally, an additional cognitive demand may have resulted from the participants' knowledge that they would be giving their sentences to me at the end of the activity. Although the participants had been instructed to not worry about spelling and grammar, using the new words in sentences that they would have to turn in could have added an additional stress that interfered with the formation of meaning-based connections in the lexicon.

\section{Subcategories}

Within the meaning-specific subcategories (equivalent meaning and nonequivalent meaning), there was not a significant difference between the highfrequency word responses and the low-frequency word responses for either the control or treatment group. However, each group produced more equivalent meaning responses than non-equivalent meaning responses for both high and low-frequency words. In addition, although not statistically significant, both groups produced a greater proportion of nonequivalent meaning responses for the low-frequency words than for the highfrequency words.

The higher proportion of equivalent meaning responses supports the results of Fitzpatrick (2006). In Fitzpatrick (2006), the L2 speakers' WAT responses that corresponded to equivalent meaning were greater than those that corresponded to nonequivalent meaning. Both my results and Fitzpatrick (2006) contrast with Fitzpatrick 
(2011), who found that participants produced a greater number of nonequivalent meaning responses than any other type or response for L2 cue-words.

That both the control and treatment group in this study produced more equivalent meaning responses than nonequivalent meaning responses for both high and lowfrequency words may indicate a natural tendency for words to be organized in the lexicon through connections based on synonymy, coordination, and superordination. However, it is possible that the way the low-frequency words were introduced to the participants influenced these responses. Since the participants were provided with definitions, all of which were primarily based on synonymy, coordination, or superordination, it is possible that the nature of these definitions encouraged more equivalent meaning responses to the low-frequency words.

The requirements of the vocabulary knowledge scale (VKS), which the participants completed prior to the intentional learning period and WAT may provide an alternate explanation for why the high-frequency words elicited more equivalent meaning responses than nonequivalent meaning responses. For the VKS, the participants were asked to provide a word or words to demonstrate understanding of the words they marked that they knew or thought they knew. The written instructions on the VKS asked for a synonym or translation although the participants were instructed that any word or words that demonstrated they knew the target word would be sufficient. A high percentage of both the control and treatment group's WAT responses to the high-frequency words were the same or very similar to what those participants produced on the VKS. This correspondence between WAT responses and VKS responses may indicate that the VKS acted to prime the participants to produce equivalent meaning responses during the WAT. 
Alternately, it could indicate that preexisting equivalent meaning-based connections are durable and consistently produced over time in different tasks-in this case on both the VKS and the WAT. The possible connection between VKS responses and WAT responses is discussed in more depth in the following section.

The sentence writing condition did not appear to influence the type of meaningbased responses (equivalent meaning or nonequivalent meaning) that were made. Although the sentence writing condition seemed to have the potential to develop more nonequivalent meaning-based connections in the lexicon, it did not seem to do so. The sentence writing condition seemed to have the potential to cause more nonequivalent meaning responses because it sought to encourage participants in the treatment group to engage with the target words in a way that would require those words be "analyzed, synthesized, and reworked, or associated with already-known information" (Schmitt and Schmitt, 1993) thereby potentially causing more unexpected connections to be formed in the lexicon. I had thought that these unexpected connections might have manifested as more nonequivalent meaning responses.

Even though the sentence writing task that the treatment group engaged in did not appear to affect the type of meaning-based response produced, it is interesting that both the control and treatment group gave a higher proportion of equivalent meaning responses than nonequivalent meaning responses for the high-frequency words than they did for the low-frequency words. Although this difference was not found to be statistically significant, it may still indicate that well known words tend to be more consistently organized in the lexicon through equivalent meaning-based connections than are less well known words. It is possible that as new words become more familiar, they 
become more consistently organized in the lexicon through equivalent meaning-based connections.

In spite of this possibility, it is not unrealistic to assume that well known words, like the high-frequency ones in this study, are organized in the lexicon in a robust way that includes nonequivalent meaning-based connections as well as equivalent meaningbased connections. It is possible that the predominance of equivalent meaning responses, especially to the high-frequency words, could have been influenced by what the learners thought was expected of them based on their past experiences with language learning. Often in language learning, learners are expected and encouraged to produce definitions for words as a way to evaluate whether or not those words have been learned. It is possible that this type of common evaluation of vocabulary learning influenced the type of meaning-based responses that the learners produced on the WAT.

\section{Additional Observed Patterns}

In addition to the analysis of the distribution of WAT responses across the main meaning and non-meaning categories, and the equivalent meaning and nonequivalent meaning subcategories, two additional patterns which were not anticipated prior to the data collection were observed. The first corresponds to what the participants wrote on the VKS (VKS WAT responses) and the second corresponds to the low-frequency word definitions that the students used during the intentional learning period (definition WAT responses). 
VKS WAT responses. As mentioned above, a large number of both the treatment and control group's WAT responses to the high-frequency words were identical or very similar to what they wrote on the VKS to indicate their knowledge of those words. For example, one participant wrote breathing on the VKS to demonstrate an understanding of the word life and then produced the association breathing for the cueword life in the WAT. In another case, for the word house on the VKS, one participant wrote place to live and gave the WAT response living for the cue-word house. 24 of the treatment group's analyzable WAT responses to high-frequency cue-words $(32.9 \%$ of WAT responses in this category) were these types of VKS responses. The control group produced $43 \mathrm{VKS}$ responses, which came to $58.1 \%$ of their analyzable WAT responses to high-frequency words. That so many WAT associations were also the same as, or very closely related to, words that the participants produced on the VKS may indicate the durability that specific connections have once they are activated.

This durability of lexical connections is especially well supported by three WAT responses to low-frequency words and their corresponding VKS responses. In these cases, the synonym/definition that the participant provided on the VKS revealed an erroneous understanding of the low-frequency word in question. These erroneous VKS responses were reproduced as WAT responses after the 20 minute intentional learning period. That the erroneous connections were repeated even after the participants had studied the correct definitions points to the especially strong durability of some initial connections in the lexicon. However, it is also possible that these erroneous connections are the result of low-quality learning, perhaps due to the study conditions and instructions. 
It is unclear why the control group produced a higher percentage of VKS WAT responses than the treatment group, but this may be related to the sentence writing task that the treatment group performed. The sentence writing that the treatment group did may have created interference for the connections activated by the VKS through having been more cognitively demanding.

Definition WAT responses. In addition, both the treatment and control group produced WAT associations that were also words from the cue-word's definition as it was provided to the participants during the intentional learning period. For example, a participant's WAT response ring for the cue-word atoll used a key word in the definition for atoll that was provided to the participants. The treatment group produced 22 definition WAT responses, which was $41.5 \%$ of the total analyzable responses they made for the low-frequency cue-words. The control group produced 51 definition WAT response, which was $77.3 \%$ of their analyzable WAT responses for the low-frequency cue-words. These definition WAT responses may indicate the influence that definitions have on how new words are integrated into the lexicon, which is to be expected. That the treatment group produced markedly fewer associations that were also words from the definitions may indicate the influence of the treatment task. It is possible, that by requiring the participants to use the low-frequency words in sentences, that the treatment task caused them to focus less on the specific definitions thereby causing different connections to develop in the lexicon. 


\section{Implications for Future Research}

There has been relatively little WAT research focused on how new vocabulary items are organized in the lexicon during the learning process and further research in this area is needed. The results of this study point to some specific areas that may be of interest for future research.

This study brought to light a variety of factors that may have had an unexpected influence on the WAT responses produced for both the high and low-frequency words. As discussed above, it is possible that recently activated connections from the VKS as well as the definitions that were provided to the participants may have had an influence on their WAT responses. Future WAT research could benefit from investigating the degree to which contextual factors such as these may influence WAT responses and the way new vocabulary is integrated into the lexicon.

Further investigation on the influence of these contextual factors could help to explain the exceptionally high proportion of meaning-based responses relative to nonmeaning based responses in this study. Additionally, an investigation of these contextual factors could help to better explain why equivalent meaning responses were favored in this study, as in Fitzpatrick (2006), but not in Fitzpatrick (2011).

Although this study was able to compare well known words to new vocabulary words, it was not able to investigate the possible changes in the lexicon as specific new vocabulary is further integrated into the lexicon over time. Future studies may want to take a longitudinal approach in order to investigate how new vocabulary words integrate into the mental lexicon over time in different learning conditions. 
Finally, this study used sentence writing to try and elicit deep processing from participants in the experimental group. The post-WAT debriefing indicated that the majority of the participants in the control group, while not writing sentences, were linking the target words to novel contexts and/or linking the target words to their personal experience-two techniques that also meet the conditions associated with deep processing. Since both the treatment and control group appear to have employed strategies associated with deep processing, further research may want to require participants use a strategy that could prevent or inhibit deep processing in order to investigate the way in which shallower processing may affect how new words are integrated into the lexicon.

\section{Implications for language teaching}

The results of this study have some interesting implications for vocabulary learning and teaching. As the treatment task (sentence writing) seemed to correlate with a slight decrease in the formation of meaning-based lexical connections, it is a reminder to teachers that different types of activities and learning strategies may affect lexical integration in different ways. At present, it is unclear how sentence writing at different stages of the learning process affects the way words are integrated into the lexicon over the long term. Although it is possible that sentence writing may be more effective later in the vocabulary acquisition process, it is also possible that the type of focus it elicits, even in early stages of learning, is a beneficial and necessary part of the overall learning process. 
This study also revealed the high degree of influence that definitions used to discover a word's meaning may have on the way those words are organized in the lexicon. This may indicate that teachers should pay special attention to the way they introduce vocabulary_-perhaps by providing clear definitions or key words onto which the new words' forms can be initially mapped in the lexicon. Teachers may also want to make a special point of returning to and reviewing these definitions/key words to help encourage these strong early connections. At the same time, the correlation between the VKS responses and the WAT responses may indicate that initially activated lexical connections are especially durable_-even when those connections are not accurate. Teachers may want to be especially aware of the potential durability of these early connections so that they can assist learners to expand on these initial connections to further integrate vocabulary items into the lexicon through more varied connections. Finally, given the potential durability of initially activated lexical connections, teachers may want to devote extra attention to correcting erroneous meanings.

\section{Limitations}

One limitation of this study was the relatively small number of participants. That there were only 16 participants limits the degree to which this study's results can confidently be said to represent a greater population. Additionally, a larger sample size could investigate factors not discussed in this study. The learners from this study came from a number of different nationalities and language backgrounds, but, due to the small number of participants, the study was unable to investigate what affect, if any, these factors had on the participants' WAT responses. In addition, although all the participants 
in this study were recruited from high-intermediate to advanced classes, no further assessment of their proficiency was done. More detailed assessments of their proficiency levels may have revealed differences between the participants that could have influenced the WAT results.

Another limitation of this study was the relatively small number of high and lowfrequency words used for the WAT. It was necessary to limit the number of lowfrequency words in number so that the participants would have adequate time to work with them during the intentional learning period. However, a larger number of WAT words would have allowed for the inclusion and analysis of words from more than one word class thereby providing a more robust picture of the lexicon.

Both a greater number of participants and a greater number of WAT words would have meant an overall greater number of WAT responses for analysis. Had there been more WAT responses for the analysis, it might have allowed for a more nuanced analysis that could have included a greater number of word association categories and subcategories like those used in Fitzpatrick (2006).

Another limitation relates to the responses that could not be explained in relation to the WAT categories and which were subsequently excluded from the analysis. Some responses were not intelligible on the recording. In addition, some responses that were intelligible did not appear to pertain to any of the WAT categories. The true nature of these seemingly erratic responses was not able to be determined. It is possible that they could have been meaning-based nonequivalent meaning or position responses whose relationship to the cue-word I was unable to recognize. For example, it is possible that the response watch to the cue-word day was a position response as there is a Russian film 
titled Day-Watch. However, since the participant who made this response was not a Russian speaker, it would have been overly speculative to assume that they were familiar with the film and that it inspired the WAT association. In cases like this one, where it was impossible to say with any degree of certainty what type of connection, if any, was present, the association was classified as other. Future studies may benefit from further investigating these types of responses. Asking participants about their specific WAT responses in a follow up interview would be one way to ensure that all pertinent data could be included in the analysis and might reveal interesting information about responses that would otherwise be classified as erratic.

Finally, the general subjective nature of classifying WAT responses into categories is a limitation of this study. It would have been preferable to have multiple people familiar with the WAT categories classify the WAT responses in order to provide inter-rater reliability. Additionally the subjective nature of classifying WAT responses limits the extent to which the results of this study can be compared with total confidence to other WAT studies that used, or may use, the same or similar categories. Different researchers, even those using the same WAT categories, may interpret word association categories and WAT responses differently, thereby causing variation in how WAT responses are classified across studies.

\section{Conclusion}

The importance of vocabulary learning in ELT has, since the 1980s, increasingly become recognized in English language teaching and learning. This study aimed to contribute to that body of knowledge by investigating how words are organized and 
integrated into the lexicon. To do this, this study used a word association test (WAT). Unlike most of the previous WAT research on the lexicon, this study focused on how new vocabulary items are integrated into the lexicon and compared that emerging organization to the lexical organization of well know items. In addition, this study investigated the low-frequency (unknown) vocabulary items in two conditions: one in which the participants studied without specific guidance, and one in which the participants wrote meaningful sentences with the new words.

The study revealed a strong preference for lexical organization through meaningbased associations; the majority of which were related to the cue-word through equivalent meaning-based connections. The treatment group, while still favoring meaning-based responses, produced a significantly greater number of non-meaning responses than did the control group for low-frequency words. While there are a number of factors that could have influenced this result, teachers and learners may want to be aware of the potential limitation of sentence writing activities for activating meaning-based connections in the earliest stages of the vocabulary learning process.

That both groups produced a higher number of equivalent meaning responses within the meaning-specific subcategories suggests that L2 learners' lexicons may be organized through connections based on synonymy, coordination, and superordination. In the early stages of learning, teachers may wish to provide activities that facilitate this kind of lexical integration, but may also wish to use activities that facilitate other types of connections in the lexicon later in the vocabulary learning process. 


\section{References}

Aitchison, J. (2003). Words in the mind ( $3^{\text {rd }}$ ed.). Maiden, MA: Blackwell Publishing.

Barcroft, J. (2002). Semantic and structural elaboration in L2 lexical acquisition. Language Learning, 52(2), 323-363.

Barcroft, J. (2004). Effects of sentence writing in second language lexical acquisition. Second Language Research, 20(4), 303-334. doi: 10.1191/0267658304sr233oa

Bauman, J. \& Culligan, B. (1995). About the General Service List [web page]. Retrieved from http://jbauman.com/aboutgsl.html

Beck, J. (1981). New vocabulary and the associations it provokes. Polyglot, 3(3), C7-F13.

Craik, F. \& Lockhart, R. (1972). Levels of processing: A framework for memory research. Journal of Verbal Learning and Verbal Behavior, 11(6), 671-684.

Craik, F. \& Tulving, E. (1975). Depth of processing and the retention of words in episodic memory. Journal of Experimental Psychology: Genral, 104(3), 268-294. 
Desrochers, A., Wieland, L.D., \& Cote, M. (1991). Instructional effects in the use of the mnemonic keyword method for learning German nouns and their grammatical gender. Applied Cognitive Psychology, 5, 19-36.

Fitzpatrick, T. (2006). Habits and rabbits: Word associations and the L2 lexicon. EUROSLA Yearbook, 6, 121-145.

Fitzpatrick, T. \& Izura, C. (2011). Word associations in L1 and L2: an exploratory study of response times and interlingual mediation. Studies in Second Language Acquisition, 33(3), 373-398. doi:10.1017/S0272263111000027

Folse, K. (2004). Vocabulary myths: applying second language research to classroom teaching. Ann Arbor: University of Michigan Press.

Hill, M. \& Laufer, B. (2003). Type of task, time-on-task and electronic dictionaries in incidental vocabulary learning. IRAL, 41(2), 87-106. DOI: 10.1515/iral.2003.007

Hirsh, D. \& Nation, P. (1992). What vocabulary size is needed to read an unsimplified text for pleasure? Reading in a Foreign Language, 8(2), 689-695.

Laufer, B. (2005). Focus on form in second language vocabulary learning. EUROSLA Yearbook, 5, 223-250. 
Longman. (2004). Longman dictionary of contemporary English (international ed.). Harlow, England: Pearson Education Limited

Meara, P. (1982). Word associations in a foreign language: A report on the Birkbeck Vocabulary Project. The Nottinham Linguistic Circular, 11(2), 29-38.

Nation, P. (n.d.). Range program with British National Corpus list 14,000. Victoria University, School of Linguistics and Applied Linguistics Studies, Paul Nation [web page]. Retrieved from http://www.victoria.ac.nz/lals/about/staff/paul-nation

Nation, ISP. (2001). Learning vocabulary in another language. Cambridge; New York: Cambridge University Press.

Nation, P. \& Beglar, D.. (2007). A vocabulary size test. The Language Teacher 31(7), $9-13$

Paribakht, T.S. \& Wesche, M.B. (1993). Reading comprehension and second language development in a comprehension-based ESL program. TESOL Canada Journal, 11(1), 9-29.

Schmitt, N. (2008). Instructed second language vocabulary learning. Language Teaching Research, 12(3), 329-363. doi:10.1177/1362168808089921 
Schmitt, N. \& Schmitt, D.R. (1993). Identifying and assessing vocabulary learning strategies. Thai TESOL Bulletin, 5(4), 27-33.

Singleton, D.M. (1999). Exploring the second language mental lexicon. Cambridge; New York: Cambridge University Press

Wilkins, D.A. (1972). Linguistics in language teaching. Cambridge: MIT Press

Yuping, F. (2010). The developmental route of Chinese English learners' mental lexicon: Cross-sectional and longitudinal perspectives. Chinese Journal of Applied Linguistics, 33(6), 71-90.

Zareva, A. (2007). Structure of the second language mental lexicon: how does it compare to native speakers' lexical organization? Second Language Research, 23(2), 123-153. doi: $10.1177 / 0267658307076543$ 


\section{Appendix A \\ Vocabulary Knowledge Scale}

\section{Choose the number that best describes your knowledge of the word in bold.}

example: time

1) I have never seen this word before.

2) I have seen this word before, but I don't know what it means.

3) I have seen this word before and I think it means (synonym or translation).

4) I know this word. It means (synonym or translation).

day

1) I have never seen this word before.

2) I have seen this word before, but I don't know what it means.

3) I have seen this word before and I think it means (synonym or translation).

4) I know this word. It means (synonym or translation).

\section{atoll}

1) I have never seen this word before.

2) I have seen this word before, but I don't know what it means.

3) I have seen this word before and I think it means (synonym or translation).

4) I know this word. It means (synonym or translation).

\section{hand}

1) I have never seen this word before.

2) I have seen this word before, but I don't know what it means.

3) I have seen this word before and I think it means (synonym or translation).

4) I know this word. It means (synonym or translation).

\section{coven}

1) I have never seen this word before.

2) I have seen this word before, but I don't know what it means.

3) I have seen this word before and I think it means (synonym or translation).

4) I know this word. It means (synonym or translation). 
life

1) I have never seen this word before.

2) I have seen this word before, but I don't know what it means.

3) I have seen this word before and I think it means or translation).

4) I know this word. It means ___ (synonym or translation).

\section{fealty}

1) I have never seen this word before.

2) I have seen this word before, but I don't know what it means.

3) I have seen this word before and I think it means (synonym or translation).

4) I know this word. It means (synonym or translation).

\section{house}

1) I have never seen this word before.

2) I have seen this word before, but I don't know what it means.

3) I have seen this word before and I think it means or translation). (synonym

4) I know this word. It means (synonym or translation).

\section{guile}

1) I have never seen this word before.

2) I have seen this word before, but I don't know what it means.

3) I have seen this word before and I think it means (synonym or translation).

4) I know this word. It means (synonym or translation).

\section{man}

1) I have never seen this word before.

2) I have seen this word before, but I don't know what it means.

3) I have seen this word before and I think it means (synonym or translation).

4) I know this word. It means (synonym or translation).

\section{hubris}

1) I have never seen this word before.

2) I have seen this word before, but I don't know what it means.

3) I have seen this word before and I think it means (synonym or translation).

4) I know this word. It means (synonym or translation). 
people

1) I have never seen this word before.

2) I have seen this word before, but I don't know what it means.

3) I have seen this word before and I think it means or translation).

4) I know this word. It means ___ (synonym or translation).

\section{malady}

1) I have never seen this word before.

2) I have seen this word before, but I don't know what it means.

3) I have seen this word before and I think it means (synonym or translation).

4) I know this word. It means (synonym or translation).

\section{school}

1) I have never seen this word before.

2) I have seen this word before, but I don't know what it means.

3) I have seen this word before and I think it means or translation).

4) I know this word. It means ___ (synonym or translation).

\section{sojourn}

1) I have never seen this word before.

2) I have seen this word before, but I don't know what it means.

3) I have seen this word before and I think it means (synonym or translation).

4) I know this word. It means (synonym or translation). work

1) I have never seen this word before.

2) I have seen this word before, but I don't know what it means.

3) I have seen this word before and I think it means or translation).

4) I know this word. It means (synonym or translation).

\section{trill}

1) I have never seen this word before.

2) I have seen this word before, but I don't know what it means.

3) I have seen this word before and I think it means or translation).

4) I know this word. It means (synonym or translation). (synonym (synonym (synonym 
number

1) I have never seen this word before.

2) I have seen this word before, but I don't know what it means.

3) I have seen this word before and I think it means (synonym or translation).

4) I know this word. It means ___ (synonym or translation).

plankton

1) I have never seen this word before.

2) I have seen this word before, but I don't know what it means.

3) I have seen this word before and I think it means (synonym or translation).

4) I know this word. It means (synonym or translation).

year

1) I have never seen this word before.

2) I have seen this word before, but I don't know what it means.

3) I have seen this word before and I think it means or translation). (synonym

4) I know this word. It means (synonym or translation).

\section{refectory}

1) I have never seen this word before.

2) I have seen this word before, but I don't know what it means.

3) I have seen this word before and I think it means (synonym or translation).

4) I know this word. It means (synonym or translation). 
Appendix B

Sentence Writing Worksheet

Write one or two sentences for each of the words below. Use the word in at least one of the sentences.

Example: (chair)

I have a comfortable chair at my desk, and it makes it easy for me to do work

there.

(atoll)

(coven)

(fealty)

(guile)

(hubris) 
(malady)

(sojourn)

(trill)

(plankton)

(refectory) 


\section{Appendix C Informed Consent Form}

\section{Be part of an important project investigating vocabulary learning}

My name isAdam Jones, and I am a graduate student at PSU. I would like you to participate in a study I am doing. The study will investigate vocabulary learning. The study will investigate how students learn new vocabulary and how those words are organized in the mind. If you choose to participate, you will study new vocabulary words and provide information about the words and how you learned them.

\section{What I will have to do:}

If you decide to participate in this study, you will meet with the researcher at a time that is good for you and do the following:

- You will complete a short form to provide basic information about yourself and the classes you are taking.

- You will complete a short survey that asks whether you know some words (about 5 minutes).

- You will study 10 new vocabulary words (20 minutes).

- You will give information about the vocabulary words, and how you studied them (about $15 \mathrm{~min}$ ).

- You will be tape recorded when you talk about the words and how you studied.

\section{Why have I been asked to take part in this study?}

You have been asked to participate in this study because you are over 18, in high-level IELP classes. You do not have to take part in this study.

\section{Are there any risks?}

- There is a small risk that someone will learn your name and find out what your answers are. Your name will not be used to report the results, and I will use a code name to protect your name identity.

- There is a small risk that you will feel anxiety when performing the tasks or answering the questions. If this happens, you may stop participating.

\section{What are you doing to protect me?}

Your privacy is very important to us. We have done several things to protect you:

- We won't tell anyone if you take part in this study or not.

- What you say and write will be kept confidential to the extent allowed by law. This means that the names of the people who take part in the study will only be seen by myself and possibly my academic advisor. We will only reveal what you say or do in a way that no one could ever guess or know it was you by reporting information in groups and using code names.

- When we write down what you say or produce, we will not use your name, thereby ensuring that you cannot be identified. In addition, we will leave out anything you say that could potentially identify you. 
- Your name and other personal information will be kept locked up so that no one other than the researcher will be able to see it. We need this information to keep track of who participated. For example, this form will be kept in a locked cabinet because it has your name on it.

\section{What will I gain by taking part in this study?}

- You will see and study new vocabulary words it is unlikely that you have seen before.

- You will help add to our knowledge of vocabulary learning, which may benefit both teachers and students studying English for admission to a university.

\section{What happens if I decide to not take part in this study?}

- There are no consequences if you decide not to participate in the study.

- You may decide any time that you no longer want to participate in the study and may stop your participation with no consequences by sending me, Adam Jones, an e-mail at jona@pdx.edu.

- If you decide not to participate, it will not affect your relationship with me, Adam Jones, Portland State's Department of Applied Linguistics, or with the IELP and your IELP teachers. The IELP and your IELP teachers will not be aware of your decision to participate or not participate in the study.

\section{Any questions?}

For questions about the study, you may contact me at jona@pdx.edu.

You may also Contact the Chair of the Human Subjects Committee of Portland State

University about your rights as a research participant. They can be contacted at:

Research and Strategic Partnerships

Portland State University

Market Center, Room 620

1600 SW 4th Ave.

Portland, OR 97201.

Telephone: 503-725-3423

e-mail: $\underline{\text { rsp@pdx.edu }}$ 


\section{If I sign, what does it mean?}

This is a consent form, and if you choose to sign, it means that:

- you have read this form, and you understand what this form says.

- you are willing to take part in this study by performing the tasks described above.

- you are willing to be recorded while talking about the target vocabulary words and the way you studied them.

- You understand that you do not have to participate in this study.

- You understand that you can stop your participation at any time with no consequences.

- You understand that this study is not part of the IELP program, and will not affect your relationship with the IELP program or your teachers in any way. The IELP program, and your teachers will not know that you have chosen to participate in this study.

- You will get a copy of this form for yourself.

participant signature

date

participant name (print) 
Appendix D

Demographic Information Questionnaire

What is your gender?

male

female

How old are you?

Where are you from?

What languages do you speak?

How long have you been studying English?

How long have you been in the U.S.?

What classes are you taking in the IELP currently?

$\underline{\text { Class }}$

Level

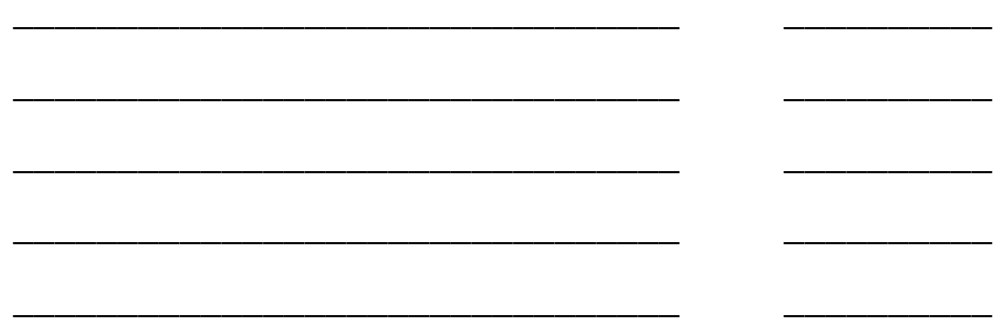

Are you taking any other PSU classes? If so, what class/classes are you taking? 